\title{
LOS RECURSOS VEGETALES EN EL MUNDO ROMANO: ESTUDIO DE LOS MACRORRESTOS BOTÁNICOS DEL YACIMIENTO CALLE SANTIAGO DE IRÚN (GUIPÚZCOA)
}

\author{
POR \\ LEONOR PEÑA-CHOCARRO Y LYDIA ZAPATA PEÑA \\ Dept. Human Environment. Institute of Archaeology. University College London.
}

\section{RESUMEN}

Se exponen los resultados del análisis arqueobotánico de tres muestras procedentes del yacimiento romano CSI (Irún, s. I - III d.C.). Corresponden a una zona portuaria en la que confluye material botánico de origen vario: vegetación estuarina y de ribera, desechos urbanos de diverso origen y especies características de un medio alterado. La población de la Oiasso romana tuvo acceso a una amplia gama de recursos vegetales tanto silvestres como cultivados. Se han identificado especies de interés económico importadas e introducidas en la zona en esta época.

\section{SUMMARY}

The results of the archaeobotanical analysis of three samples from the Roman site CSI (Irún, Basque Country, I III A.D.) are presented. They correspond to a port zone where material from different proveniences has met: estuarine and river-close areas, urban waste and altered places. The human population of the Roman Oiasso had access to a wide range of plant foods, wild as well as domestic ones. Economically interesting species which have been imported or introduced at this time have been identified.

\section{INTRODUCCIÓN}

El valor arqueológico del municipio de Irún, antiguo centro romano de Oiasso, se conoce desde hace tiempo. Debido a la instalación de nuevos colectores de aguas residuales en la calle Santiago, junto a la parroquia del Juncal, el Centro de Estudios Históricos y Arqueológicos ArKeolan llevó a cabo unos sondeos en el casco urbano bajo la dirección de Mercedes Urteaga. Tras los resultados positivos de estos trabajos, se realizó una excavación arqueológica que puso al descubierto varios elementos de la zona portuaria del Irún romano: un muelle para uso de las embarcaciones y restos de edificios situados en la orilla del estuario. El relleno de las estructuras se realizó mediante la acumulación intencional de residuos procedentes de desechos urbanos: vajillas rotas, fragmentos de ladrillo y teja así como basuras procedentes del consumo humano (Urteaga y López, 1994; Urteaga, 1995).
El medio húmedo en el que se encontraba el yacimiento, a tres metros de profundidad y cubierto por una capa de limo, permitió una excelente conservación en condiciones anaeróbicas de abundante material orgánico entre el que destacaba una estructura de madera, única en la cornisa cantábrica. También se recuperaron otros objetos de cuero y madera de época romana con una preservación excepcional. Por supuesto, este magnífico grado de conservación de materiales orgánicos, nada frecuente en yacimientos arqueológicos peninsulares, se hace extensivo a los restos vegetales como semillas y frutos que son el objetivo de este trabajo. Durante la excavación, se identificaron y recogieron in situ numerosos macrorrestos vegetales asociados al material arqueológico y a las estructuras mencionadas: huesos de Persica vulgaris (melocotón), fragmentos de pericarpo o cáscara de Corylus avellana (avellana) y capas de Juncáceas.

En Guipúzcoa, a pesar de que existen hallazgos romanos en otras zonas, destaca en cuanto a restos de esta época la zona oriental del territorio (yacimientos de Santa Elena, Cabo de Higuer, Minas de Arditurri), alrededor del río Bidasoa. Es aquí donde se encuentra la ciudad de Oiasso (Irún) (Benito, 1988; Santos, 1989), un centro de alto interés para la comprensión de la romanización del País Vasco. La escasez actual de datos no permite tener una visión global de este fenómeno ya que tradicionalmente la investigación arqueológica del País se ha centrado en otras etapas, preferentemente prehistóricas (Santos, 1989). Si esto es verdad para el estudio de los materiales arqueológicos tradicionales (cerámica, vidrio, estructuras, etc.) lo es mucho más en lo que respecta al material arqueobotánico, que es uno de los grandes desconocidos. Afortunadamente, este panorama está cambiando y comienzan a realizarse en el País Vasco trabajos arqueológicos relacionados con la época romana (VV.AA.: Arkeoikuska).

Cabe destacar dos hechos relativos a este yaci- 
miento. Calle Santiago es uno de los pocos yacimientos arqueológicos peninsulares en los que el material orgánico se ha conservado en condiciones húmedas. Por otro lado, los resultados de Irún son los primeros datos de primera mano que tenemos acerca de la utilización e importación de especies vegetales en época romana para la cornisa cantábrica.

A la espera de recibir dataciones dendrocronológicas más precisas, el material arqueológico recuperado en el depósito excavado parece enmarcarse entre los siglos I y principios del III de nuestra era, sin que se hayan detectado intrusiones de otros momentos posteriores al romano. Asumimos por lo tanto que el material botánico es contemporáneo al resto del depósito.

\section{OBJETIVOS}

La arqueoetnobotánica es la disciplina que se ocupa del análisis e interpretación de los restos vegetales procedentes de contextos arqueológicos con el fin de proporcionar información sobre la interacción de las poblaciones humanas con las plantas en el pasado (Hastorf y Popper, 1988). Este estudio pretende cumplir tanto objetivos generales de la arqueobotánica como otros más específicos referentes a la problemática que plantea el mundo romano:

- Estudiar los ecosistemas del pasado en Irún atendiendo sobre todo a la distribución de recursos susceptibles de aprovechamiento humano.

- Identificar cuáles son los recursos vegetales utilizados por la población de Irún en época romana y conocer su importancia económica.

- Evaluar la importancia de la recolección de recursos vegetales silvestres.

- Conocer la agricultura y horticultura desarrollada en el País Vasco en época romana: especies utilizadas, la flora asociada, técnicas de producción.

- Delimitar la existencia de especies de nueva aparición introducidas en el País Vasco o importadas por los romanos.

- Aportar datos sobre la funcionalidad y formación del depósito muestreado.

- Definir el impacto antrópico sobre el medio natural en la Antigüedad.

Pensamos que gran parte de los objetivos propuestos se han cumplido. Las limitaciones en la interpretación arqueológica se deben a que se trata de una excavación en un área reducida con relación al conjunto de la ciudad. Además, las características del contexto y la calidad y diversidad de los restos botánicos no han permitido profundizar en algunas de las cuestiones planteadas (básicamente las relacionadas con la ecología y las prácticas agrícolas).

\section{METODOLOGÍA: ESTRATEGIA DE MUESTREO Y TÉCNICAS DE PROCESAMIENTO}

Las muestras de tierra que procesamos para extraer el material botánico procedían de tres unidades estratigráficas diferentes correspondientes a las dos fases que se han reconocido en el yacimiento de la calle Santiago de Irún (CSI). Las muestras se han denominado siguiendo la numeración de dichas unidades: CSI - 1, CSI - 8 y CSI - 110. Proceden del relleno de la zona portuaria de Irún y corresponden a la siguiente cronología:

- CSI - 110: fase de fundación de las instalaciones portuarias. Se corresponde con la construcción del muelle hacia la segunda mitad del siglo i d. C.

- CSI - 1 y CSI - 8: fase de ampliación, marcada por la construcción de una escollera de piedra hacia finales del siglo II o principios del III d. C.

La recuperación de los macrorrestos exigió un procesamiento de la tierra diferente al método de flotación habitual en las excavaciones de zonas templadas (v. 1). Los restos de Irún, conservados por inundación, exigían ser procesados y mantenidos en un medio húmedo durante toda la fase de estudio. Se procedió por lo tanto al cribado con agua de las muestras en una torre de tamices. En un primer lugar, se procesó medio litro de sedimento por muestra. Tras un primer examen y considerando que la frecuencia de aparición de los macrorrestos vegetales era insuficiente, se decidió volver a cribar un litro de sedimento por muestra. La tierra fue lavada con agua en una torre de tamices de $2 \mathrm{~mm}$., $1 \mathrm{~mm}$., $0,5 \mathrm{~mm}$., $0,25 \mathrm{~mm}$. Esto permitió la recuperación íntegra incluso de las semillas de menor tamaño. Las muestras se almacenaron en una mezcla de agua destilada $(20 \%)$ con formol al $4 \%(10 \%)$ y alcohol industrial al $10 \%(70 \%)$. A continuación se procedió a la identificación de las mismas utilizando una lupa binocular.

La lista de semillas identificadas en cada muestra se presenta en la Tabla 1 siguiendo un orden taxonómico según Aseguinolaza et al. (1984). Se ha optado por no realizar ningún análisis cuantitativo con estos datos debido al bajo número de contextos estudiados y a problemas de índole arqueológica y botánica que se explicarán posteriormente. 


\section{RESULTADOS}

Los resultados totales del análisis de las tres muestras del yacimiento de la calle Santiago de Irún se pueden observar en la Tabla 1 . Se han reconocido un total de 62 táxones, sin incluir los que fueron recogidos in situ (Tabla 2). Las muestras CSI - 1 y CSI - 8 presentan una frecuencia de restos botánicos parecida: 213 la primera y 198 la segunda. Son un poco más elevados los de CSI - 110: 326. En cuanto a la variedad de táxones, ésta es bastante similar siendo la más rica la muestra CSI - 8 con 42 .

Tabla 1.-Relación de especies y número absoluto de semillas halladas en cada contexto

\begin{tabular}{|c|c|c|c|c|}
\hline Especie & Nombre vulgar & $\begin{array}{l}\text { CSI-1 } \\
\text { Fase } 2\end{array}$ & $\begin{array}{l}\text { CSI-8 } \\
\text { Fase } 2\end{array}$ & $\begin{array}{l}\text { CSI-110 } \\
\text { Fase } 1\end{array}$ \\
\hline Triticum sp. & Trigo & & & 1 \\
\hline Salix sp. & Sauce & 2 & 9 & \\
\hline Juglans regia $\mathrm{L}$. & Nogal & * & * & \\
\hline Juglans regia L. (fruto inmaduro) & & & 1 & \\
\hline Alnus glutinosa (L) Gaertner & Aliso & & 3 & \\
\hline Coryllus avellana $\mathrm{L}$. & Avellano & * & * & * \\
\hline Ficus carica L. & Higuera & 6 & 21 & 116 \\
\hline Urtica dioica $\mathrm{L}$. & Ortiga & & & 1 \\
\hline Polygonum aviculare L. & Lengua de pájaro & 3 & 2 & \\
\hline Polygonum hydropiper L. & Pimiento de agua & & 1 & \\
\hline Polygonum persicaria L. & Persicaria & 1 & 1 & 3 \\
\hline Polygonum lapathifolium L. & & & & 1 \\
\hline Polygonum sp. & & 1 & 1 & \\
\hline Rumex acetosella L. & Acederilla & & 1 & 3 \\
\hline ? Rumex aquaticus L. & & & & 4 \\
\hline Rumex crispus/acetosa/obtusifolius & Acedera & 2 & 1 & 3 \\
\hline Rumex sanguineus/conglomeratus & & 3 & 1 & \\
\hline Chenopodium album L. & Cenizo & & 1 & \\
\hline Chenopodium sp. & & & 2 & \\
\hline Atriplex spp. & & & 6 & 3 \\
\hline Suaeda maritima (L.) & & & 2 & 4 \\
\hline Chenopodiaceae & & & 2 & \\
\hline Stellaria media (L.) & Pamplina & & & 2 \\
\hline Ranunculus acris/bulbosus/repens & & 14 & 2 & 2 \\
\hline ? Ranunculus sardous Crantz & Botón de oro & 2 & & \\
\hline ? Renunculus flammula L. & & & 3 & 2 \\
\hline $\begin{array}{l}\text { Coronopus squamatus (Forskål) } \\
\text { Ascherson }\end{array}$ & & & 1 & \\
\hline Brassica sp. & & 3 & & \\
\hline Cruciferae & & & 1 & \\
\hline Sedum sp. & Uva de gato & & 4 & 7 \\
\hline Rubus agg. fruticous & Zarza & 16 & 29 & 61 \\
\hline ? Potentilla palustris & & & & 11 \\
\hline Potentilla sp. & Tormentilla & 2 & 1 & 10 \\
\hline Alchemilla sp. & Alquemila & 3 & & \\
\hline Prunus spinosa L. & Endrino & & 2 & 1 \\
\hline Prunus domestica/insititia & Ciruelo & & 2 & \\
\hline Prunus cerasus vulgaris & Guindo & 5 & 2 & 4 \\
\hline Vitis vinifera L. & Vid & 1 & 9 & 1 \\
\hline Hypericum sp. & Androsemo & 1 & & \\
\hline Viola sp. & Violeta & & 1 & \\
\hline Conium maculatum L. & Cicuta & & & 1 \\
\hline Apium graveolens L. & Apio & 5 & 13 & 3 \\
\hline Arbutus unedo L. & Borto & & 1 & \\
\hline Anagallis tenella (L.) L. & & 4 & & 8 \\
\hline Olea europaea L. & Olivo & 2 & & \\
\hline Galium sp. & Galio & 8 & & \\
\hline Verbena officinalis $\mathrm{L}$. & Verbena & 1 & & \\
\hline
\end{tabular}


Tabla 1.-Relación de especies y número absoluto de semillas halladas en cada contexto (Cont.)

\begin{tabular}{|c|c|c|c|c|}
\hline Especie & Nombre vulgar & $\begin{array}{c}\text { CSI-1 } \\
\text { Fase } 2\end{array}$ & $\begin{array}{c}\text { CSI-8 } \\
\text { Fase } 2\end{array}$ & $\begin{array}{l}\text { CSI-110 } \\
\text { Fase } 1\end{array}$ \\
\hline Mentha sp. & Menta & 6 & 3 & 4 \\
\hline Satureja sp. & & & 2 & 1 \\
\hline Prunella vulgaris L. & & 34 & 6 & 4 \\
\hline ? Veronica sp. & & & 1 & \\
\hline Erigeron sp. & & & & 1 \\
\hline Chrysantemum sp. & & 1 & & \\
\hline Cirsium sp. & Cardo & 1 & 1 & \\
\hline Potamogeton sp. & & & & 2 \\
\hline Juncus sp. & Junco & 49 & 32 & 24 \\
\hline ? Poa pratensis/trivialis & & 4 & 1 & 29 \\
\hline Gramineae indet. (Cariópside) & & 1 & & 3 \\
\hline $\begin{array}{l}\text { Gramineae indet. } \\
\text { (Cariópside carbonizada) }\end{array}$ & & & & 1 \\
\hline Gramineae indet. (Raquis) & & & 1 & \\
\hline Gramineae indet. (Entrenudo) & & & & 1 \\
\hline Carex spp. & Espadaña & 22 & 12 & \\
\hline Indeterminadas & & 10 & 13 & 3 \\
\hline TOTAL DE RESTOS & & 213 & 198 & 336 \\
\hline TOTAL DE TÁXONES & & 32 & 42 & 36 \\
\hline
\end{tabular}

* No cuantificable. Corresponde a fragmentos de cáscaras del fruto: endocarpo (nuez) o pericarpo (avellana).

Tabla 2.-Macrorrestos vegetales comestibles recuperados in situ durante la excavación

\begin{tabular}{|l|c|c|c|c|c|}
\hline \multicolumn{1}{|c|}{ Especie } & Nombre vulgar & CSI-7 & CSI-39 & CSI-4I & CSI-57 \\
\hline Persica vulgaris Miller & Melocotón & 1 & 1 & & 2 \\
\hline Corylus avellana L. (fruto entero) & Avellana & & & 1 & \\
\hline
\end{tabular}

Atendiendo al uso potencial de las plantas identificadas se pueden distinguir varios grupos:

\section{a. Plantas de importancia económica: cultivadas y recolectadas}

Son un grupo de especies que proporcionan información de alto interés arqueológico. Para algunas de estas plantas éste es el primer dato que tenemos de su existencia en el País Vasco, por lo que cabría pensar en una introducción de su cultivo en época romana. La información que ofrecen para el arqueólogo se centra en los modos de subsistencia y dieta de la población estudiada así como en la economía del yacimiento: producción de alimentos, existencia de actividades comerciales, etc. Entre este grupo de táxones se ha identificado un único grano de trigo carbonizado (Triticum sp.) cuya especie ha sido imposible determinar. Otras especies de importancia económica que también se han documentado son: Vitis vinifera (vid. fig. 1), Rubus agg. fruticosus (mora), Prunus spinosa (endrino), Prunus domesti- ca/insititia (ciruelo), Prunus cerasus vulgaris (guindo), Ficus carica (higuera), Juglans regia (nogal; fig. 2), Corylus avellana (avellano), Arbutus unedo (madroño o borto), Olea europaea (olivo). Además, se recogieron in situ varios huesos de Persica vulgaris (melocotón).

Las plantas cultivadas, locales o importadas, han sido utilizadas en este yacimiento con toda probabilidad para el consumo humano (trigo, olivo, vid, higo...). Asimismo, el hallazgo de frutos silvestres comestibles suele ser muy frecuente en los yacimientos arqueológicos. Incluso entre culturas agrícolas, las plantas silvestres constituyen una importante, periódica y segura fuente de recursos alimenticios, medicinas o materia prima artesanal (Zohary y Hopf, 1993). Se podría argumentar que Rubus, Prunus spinosa, Juglans regia y Corylus avellana ya existían con anterioridad en el País Vasco y que su hallazgo puede ser producto del azar. Sin embargo, el contexto arqueológico urbano en el que se han hallado hace que nos inclinemos por considerarlas restos de consumo humano. 


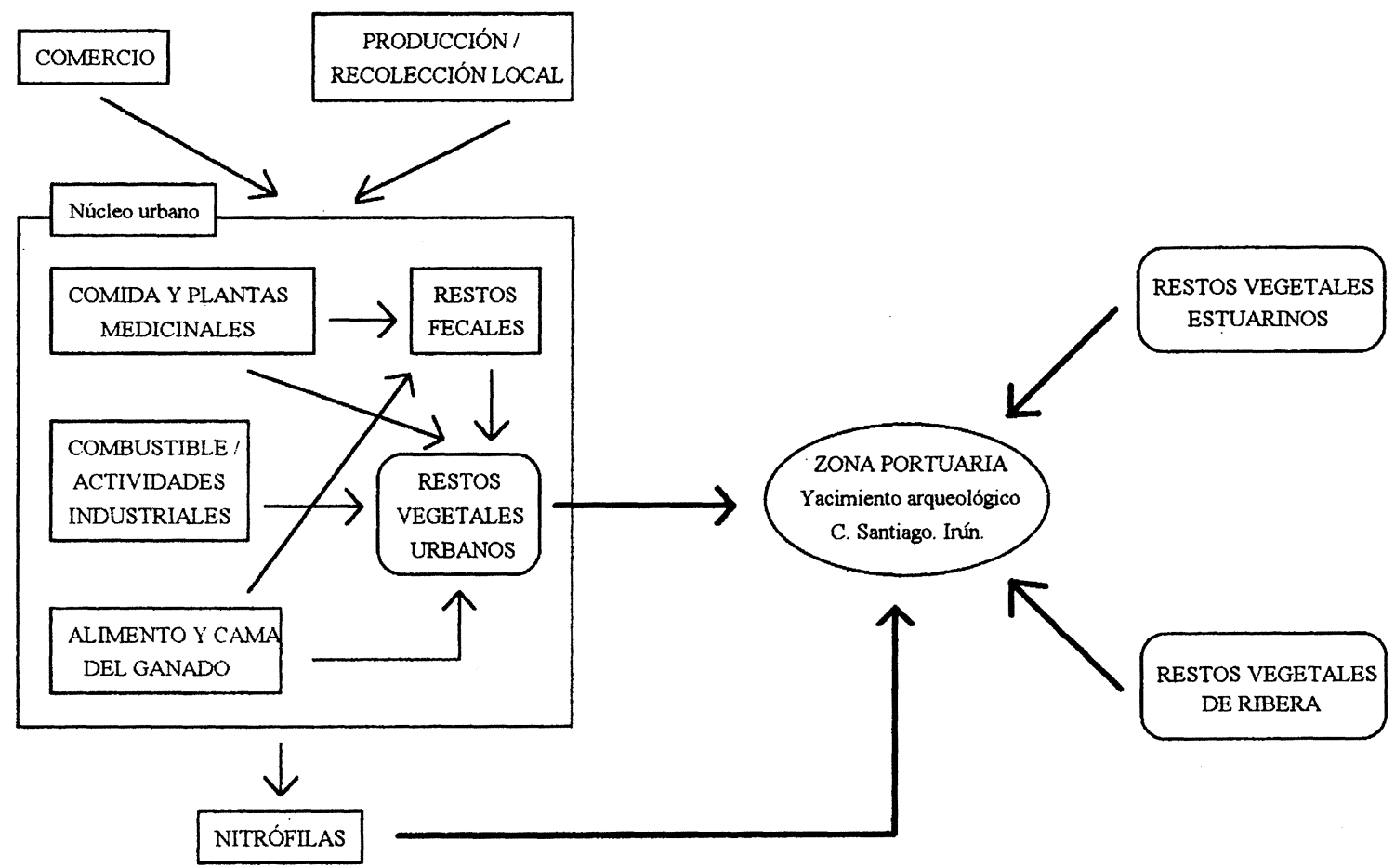

Figura 1.-Modelo teórico de llegada de restos vegetales al yacimiento arqueológico romano de la calle Santiago. Irún.

b. Plantas que potencialmente han podido utilizarse para la alimentación o uso humano aunque también pueden encontrarse de forma natural en el entorno.

Se trata de un grupo de especies no importadas en época romana cuyas semillas han podido llegar al yacimiento bien como parte integrante de la flora de la zona o bien como subproductos del consumo humano. Por el momento no podemos más que especular con estas posibilidades sin llegar a afirmar o negar rotundamente su empleo en el Irún romano (v. 5.1). Son comestibles como verdura varias especies del género Brassica como Brassica oleracea (col, berza, coliflor, brécol), Brassica napus (nabo, colza), Brassica campestris (mostaza) o Brassica nigra (mostaza negra), algunas de ellas muy apreciadas por los romanos y cuyo cultivo está bien documentado en esta época para otras zonas del Imperio (Langer y Hill, 1981). También son comestibles (Rivera y Obón de Castro, 1991) otras brasicáceas o crucíferas como Sinapis arvensis (la mostaza silvestre), Raphanus raphanistrum (rábano silvestre) o Crambe maritima (col marina). En el yacimiento gallego romano de Castro de Viladonga se ha identificado un conjunto de semillas carbonizadas de Brassica que se ha puesto en relación con la exis- tencia de un suelo de cultivo contemporáneo a la ocupación del poblado (Ramil, 1993).

La pamplina, Stellaria media (cariofilácea), también puede ser empleada para consumo humano al igual que varias quenopodiáceas entre las que se encuentra Atriplex hortensis (armuelle), utilizada como verdura en época romana y Chenopodium al-

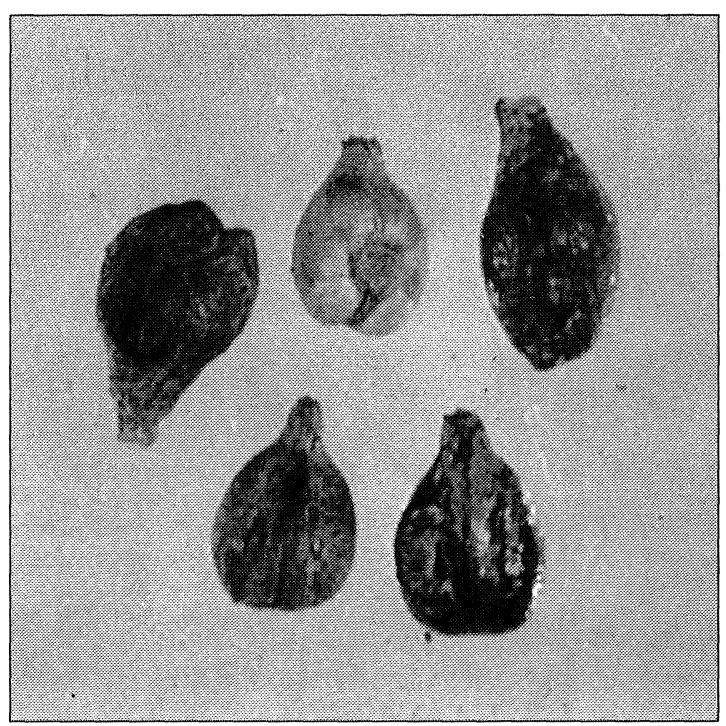

Figura 2.-Vitis vinifera L. (vid). Escala: $1 \mathrm{~mm}$. 
bum (cenizo). Así mismo, para época histórica, se conoce el uso de semillas de esta especie mezcladas con centeno para hacer pan. Entre las rosáceas, además de las especies domésticas, quizá importadas por los romanos, se puede comer la alquemila y entre las Poligonáceas, las acederas (Rumex acetosa y Rumex acetosella). Urtica dioica L. (la ortiga) también tiene aplicaciones medicinales además de ser comestible. Otros táxones identificados en las muestras que incluyen especies que potencialmente han podido ser consumidas son Veronica (escrofulariáceas) así como Satureja y Prunella Vulgaris L. en la familia de las labiadas (Genders, 1988; García, 1992; Gerard, 1985; Rivera y Obón de Castro, 1991).

Además, tienen aplicaciones medicinales las violáceas, hipericáceas, algunas Potentilla, Apium graveolens (apio), Polygonum aviculare (lengua de pájaro o centinodia), Salix (sauce), Verbena officinalis L. (fig. 3), Mentha y Galium (Vázquez, 1991).

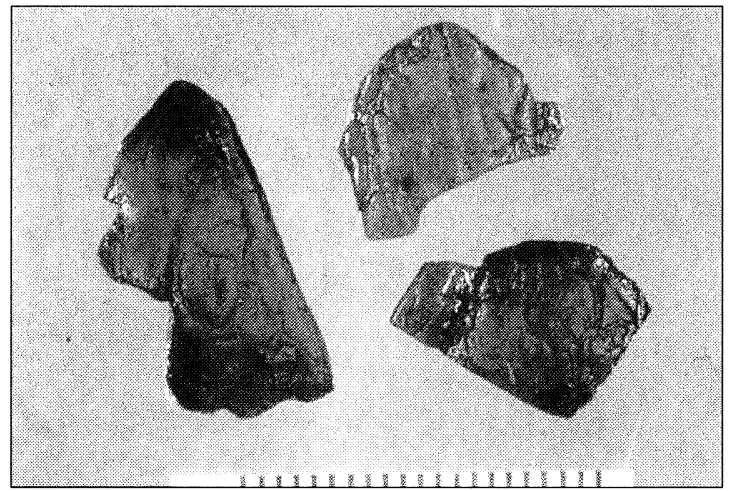

Figura 3.-Juglans regia L. (nogal). Escala: $1 \mathrm{~mm}$.

A pesar de ello, insistimos en que la mayoría de las semillas de plantas silvestres pueden tener un origen múltiple. Son especies que responden perfectamente a la ecología de la zona, por lo que es totalmente aceptable pensar que se incorporaron al yacimiento como representantes de la vegetación local.

\section{c. Otras plantas}

Las plantas que reflejan el medio natural que rodeaba al yacimiento suelen formar un grupo importante dentro de cualquier análisis arqueobotánico de material conservado en condiciones húmedas. Estas especies proporcionan información de tipo ecológico y permiten a veces llevar a cabo trabajos de reconstrucción medioambiental así como de estudio de la vegetación de la época. En el yaci- miento que nos ocupa y debido básicamente a problemas tafonómicos y de formación del depósito arqueológico (v. 5.1), tendremos que ser muy cautas con la interpretación. A grandes rasgos, los táxones identificados reflejan la diferente vegetación que confluye en el área estudiada.

En un tipo de ecosistema como el del puerto del antiguo Irún, en el estuario del Bidasoa, las plantas están adaptadas a soportar la salinidad producida por las sucesivas mareas (Aseguinolaza et al., 1989) y reflejan por lo tanto algunas de las diferentes bandas de vegetación que caracterizan las zonas de marismas. Entre las que se han identificado se encuentra por ejemplo Suaeda maritima (fig. 4), que

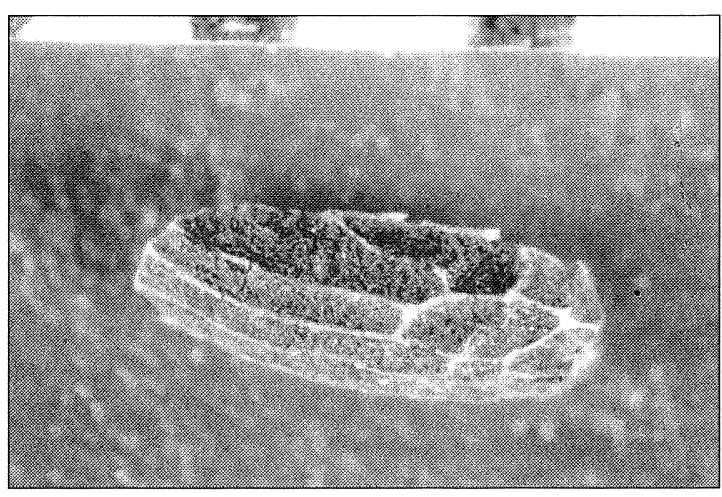

Figura 4._Verbena officinalis L. (verbena). Escala $1 \mathrm{~mm}$.

es una planta de zonas salobres, al igual que otras plantas de la familia de las quenopodiáceas (Chenopodium spp. y Atriplex spp.) (fig. 5). (Sánchez Goñi, e.p.).

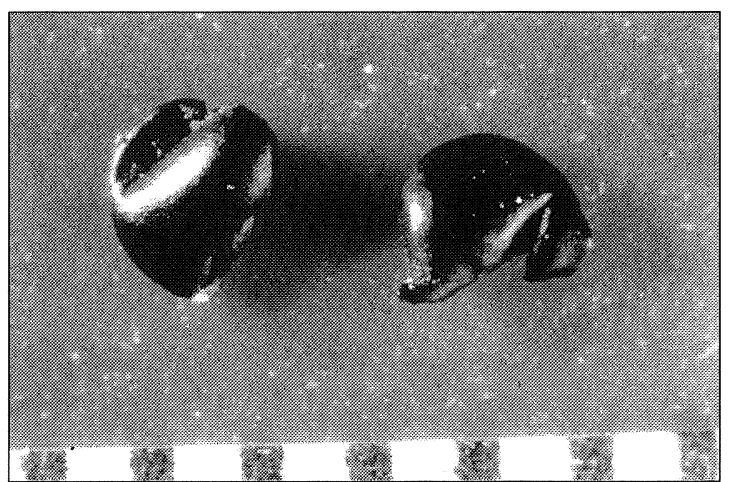

Figura 5.-Suaeda maritima (L.). Escala $1 \mathrm{~mm}$.

Debido a la influencia del agua dulce, se halla representada también en las muestras analizadas la típica vegetación de ribera cuyas semillas, en nuestro caso, han sido probablemente transportadas por 


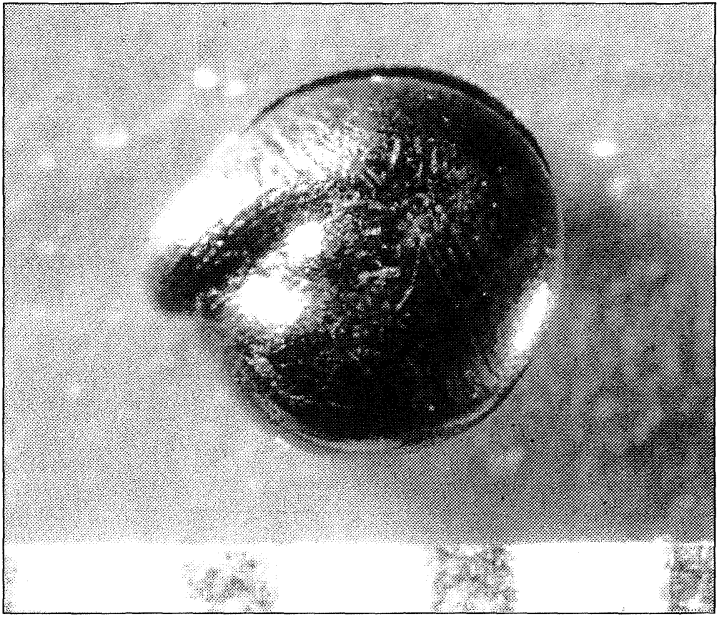

Figura 6.-Atriplex spp. Escala $1 \mathrm{~mm}$.

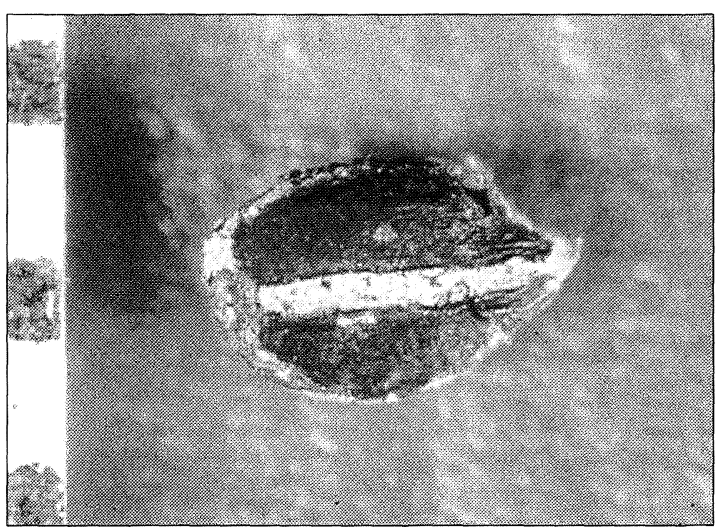

Figura 7.-Prunella vulgaris L. Escala: $1 \mathrm{~mm}$.

el río Bidasoa. Especies como Alnus glutinosa (aliso) y Salix (sauce) son buenos ejemplos de ello. Existe un gran grupo de táxones identificados en el yacimiento en cuyo medio la presencia del agua puede ser habitual; es el caso de Ranunculus, Apium graveolens, Anagallis tenella, Potamogeton y algunas especies de Polygonum y de Rumex. En algunos casos, su identificación ha quedado limitada al género, por lo que su tolerancia a la salinidad y su hábitat potencial es imposible de determinar con exactitud. Este sería por ejemplo el caso de los Juncus y Carex.

Además de la vegetación ligada al agua, hay otro grupo de especies nitrófilas que normalmente se corresponden con zonas alteradas por la actividad humana: Coronopus squamatus, Stellaria media, Conium maculatum, las especies de Polygonum y Rumex, Urtica dioica, Prunella vulgaris y Verbena officinalis. Como ya hemos visto, algunas de ellas son comestibles, tienen aplicaciones medicinales o son altamente tóxicas.

\section{INTERPRETACIÓN}

\subsection{Problemas de la interpretación arqueológica $y$ medioambiental}

La interpretación - tanto arqueológica como ecológica- de los macrorrestos vegetales de procedencia arqueológica no es fácil, ya que existen una serie de factores que condicionan la composición de la muestra analizada. Frecuentemente, este tipo de restos son las únicas evidencias con las que contamos para estudiar aspectos como la composición del paisaje vegetal de la época o la dieta del grupo humano que habitó el yacimiento, y por ello intentamos obtener el máximo de información de los restos recuperados. Sin embargo, hay que ser conscientes de los problemas y sesgos que existen, tanto generales para el estudio del material botánico como particulares para el estudio de cada yacimiento. Estos problemas han sido ya tratados por varios autores (De Moulins, 1990; Green, 1982; Wilcox, 1977) y son de dos tipos, arqueológicos y botánicos.

La naturaleza artificial de los depósitos arqueológicos urbanos es determinante a la hora de interpretar los macrorrestos vegetales de un yacimiento como el de la calle Santiago de Irún. Las actividades humanas provocan la alteración del medio natural y por lo tanto se hace difícil realizar una interpretación ecológica de los restos, ya que desconocemos la procedencia de la mayoría de los táxones. El ser humano es uno de los mayores agentes de transporte de vegetales y por ello puede resultar imposible determinar si una planta es autóctona o no. Los principios ecológicos que se pueden aplicar a los depósitos naturales son inútiles en este tipo de yacimientos debido a factores de origen antrópico.

En yacimientos arqueológicos los resultados del análisis botánico a veces están más relacionados con el tipo de contexto que se muestrea y con su función que con la economía o el paisaje vegetal del yacimiento. Las concentraciones urbanas favorecen también la aparición de plantas nitrófilas como consecuencia de la alteración del medio. El modo de conservación que presenta el yacimiento puede así mismo condicionar el tipo de restos que obtengamos. En un yacimiento como el del puerto de Irún, con condiciones húmedas, se conservan todo tipo de restos, tanto los recolectados deliberadamente como los depositados de forma natural, con lo cual la distinción entre unos y otros es más difícil. En contextos que presentan restos vegetales carbonizados (hogares, suelos de habitación, áreas de almacenamiento, etc.) la acción humana suele ser más evi- 
dente y la interpretación cuenta con datos adicionales. Así, en el caso de Irún, ayudarían a discernir si algunas de las especies silvestres documentadas pudieron haberse utilizado en la alimentación o bien se trata de especies cuya presencia en el yacimiento se debe a otros factores. Si en el futuro se excavan en extensión otras zonas del yacimiento de Irún, sería de alto interés poder realizar muestreos de las diferentes estructuras que lo componen (zonas de habitación, industriales, comerciales y de almacenamiento...) ya que la información obtenida en cuanto al aprovechamiento de productos vegetales, prácticas agrícolas y comerciales, sería mucho más completa que la actual.

Otro aspecto que desconocemos es si la representación de táxones obtenida en el análisis se corresponde con la realidad del pasado, ya que han podido existir especies en las que no se consume la semilla pero cuyas hojas, por ejemplo, han podido ser trasladadas al yacimiento. Las partes blandas de la planta se conservan raramente, así que la información que tenemos sobre la utilización de los recursos vegetales silvestres es casi siempre parcial. Aunque la arqueobotánica ofrece abundante documentación sobre especies recolectadas por sus semillas o frutos, sabemos muy poco del uso de plantas medicinales, comidas utilizadas en ensalada o tubérculos y bulbos (Zohary y Hopf, 1993) ya que se trata de alimentos vegetales que no dejan huella arqueológica alguna. Recientemente se ha abierto en el mundo anglosajón una vía de investigación sobre la identificación de tejidos parenquimatosos carbonizados (Hather, 1993) que permite reconocer restos de tubérculos, bulbos, raíces y rizomas como ya se ha hecho en un yacimiento arqueológico peninsular (Peña Chocarro, 1995a, 1995b). Para el mundo romano existen más datos que para la Prehistoria debido a la amplia evidencia escrita que existe sobre el tema. En grandes zonas del Imperio se sabe qué plantas se cultivaban, cuáles se recolectaban y además existe abundante literatura sobre la alimentación y la medicina. Sin embargo, para el País Vasco los documentos clásicos son escasos y la investigación arqueológica no se ha detenido hasta ahora en la alimentación vegetal.

Otra dificultad de tipo arqueológico es que muchas veces desconocemos la dinámica exacta de formación del depósito con el que estamos trabajando: puede haberse formado en un único momento, en varios, o ser producto de una acumulación más o menos larga en el tiempo. La homogeneidad cronológica del abundante material arqueológico (numismático, cerámico, vidrio...) recuperado en el yacimiento romano de la calle Santiago de Irún hace pensar que la acumulación del sedimento que hemos procesado para cada fase se realizó en un período de tiempo corto, quizá como resultado de los trabajos de acondicionamiento de la zona portuaria del Irún romano, formando parte del relleno de las obras procedente de vertidos urbanos. Por esta razón, las posibilidades de contaminación con elementos intrusivos posteriores (Jones et al., 1991) quedan reducidas y podemos decir que los restos que hemos analizado se enmarcan entre los siglos I y III de nuestra era.

Además de los arqueológicos, otro tipo de problemas con los que nos encontramos en la interpretación son los de índole botánica y tienen que ver con la frecuencia de cada especie en el yacimiento. Las semillas muestran una conservación y longevidad diferencial antes de ser inundadas por el agua y por lo tanto conservadas en condiciones anaeróbicas. Existen especies en las que la «capa» externa es dura, lo que evita que la semilla se destruya en condiciones adversas. Entre las identificadas en Irún, sería el caso de Carex, Polygonum y Rumex. Por otra parte, como mecanismo de defensa de la planta frente a la predación o a la competición, algunas especies producen cantidades masivas de semillas y por lo tanto tienden a estar sobrerrepresentadas. Este sería el caso de Juncus spp., Hypericum, Stellaria o Ficus. Ello implica que el número de semillas identificadas en una muestra arqueológica no tiene necesariamente relación con el número de plantas de esa especie existentes en la zona en la época estudiada, y la sola presencia de una especie en una muestra arqueobotánica, aunque la frecuencia sea baja, puede ser importante (De Moulins, 1990). Un problema adicional es que muchos restos no se han identificado a nivel de especie, por lo que han podido quedar englobadas en un mismo taxon especies aprovechables con otras que no lo son. Por todos estos motivos y por las características del contexto muestreado, con alta probabilidad de que los materiales sean fruto de un depósito secundario (relleno del puerto con desechos urbanos), hemos decidido excluir un análisis de tipo cuantitativo o estadístico y hemos optado por realizar un estudio de presencia de especies (Hubbard, 1976).

\subsection{Vias de llegada de las plantas al yacimiento}

A pesar de los problemas ya señalados, relacionados no solamente con el carácter urbano del yacimiento y con los restos botánicos en sí, sino también con el tipo de muestreo realizado (limitado a una zona pequeña de lo que sería el Irún romano), 
se pueden apuntar algunas de las vías teóricas de llegada del material vegetal al área excavada (fig 1).

En las muestras analizadas se han hallado táxones propios de zonas de estuario con especies tolerantes de salinidad (Suaeda maritima y otras quenopodiáceas). Además, existen otras, características de zonas de ribera (sauces y alisos), que podrían proceder de aguas arriba del Bidasoa y cuyas semillas probablemente han sido transportadas por el propio río o el viento dado su pequeño tamaño. La confluencia de dos tipos de medio (aguas saladas procedentes de las entradas de mar con las mareas y aguas dulces procedentes del Bidasoa) provoca la presencia de especies de uno y otro ecosistema, así como de especies adaptadas a estadios intermedios entre uno y otro y numerosos táxones propios de zonas encharcadas o de otras donde la presencia de agua es importante. Este sería el caso, como ya se ha señalado antes, de muchas especies de Polygonum, Rumex, Ranunculus, etc., que además se asocian a zonas nitrogenadas propias de áreas fuertemente alteradas por el hombre, como sería una zona portuaria próxima a un núcleo urbano. Otras nitrófilas que se desarrollarían en las inmediaciones del yacimiento son especies como Coronopus squamatus, Stellaria media, Conium maculatum, Urtica dioica, Prunella vulgaris y Verbena officinalis.

Las áreas urbanas han actuado desde la Antigüedad como grandes receptoras y redistribuidoras de multitud de materiales de origen diverso. Los restos vegetales podrían ser el resultado de la producción (mediante la agricultura y la horticultura) y de la recolección local o, por el contrario, proceder de zonas alejadas y ser resultado de actividades comerciales. Fruto de estas actividades comerciales puede ser la presencia de muchas de las especies de importancia económica identificadas (melocotón, aceituna, cereza, ciruelas, higos, etc.). Está ampliamente documentada para época romana la existencia de un importante comercio de productos alimenticios entre los que se incluyen: aceitunas, trigo, cebada, manzanas, peras, cerezas, ciruelas, melocotones, membrillos, higos, nueces, lentejas, dátiles y tintes vegetales (Callender, 1965; Parker, 1973; Wilcox, 1977). Gran parte de las exportaciones romanas procedían de las penínsulas ibérica e itálica. La situación excepcional de la ciudad de Irún la convertiría no sólo en receptora de productos exóticos para el área atlántica (como el olivo) sino también en redistribuidora de mercancías destinadas a otras zonas del Imperio.

Es posible que otras plantas (uva, moras, endrinas, nueces, avellanas, etc.) crecieran de forma espontánea en las inmediaciones de la ciudad y que su incorporación al depósito se produjera de forma accidental. Sin embargo, pensamos que, debido al carácter urbano de Irún, es muy probable que su llegada a la zona portuaria se produjera como subproducto o desecho alimenticio del propio núcleo urbano. En el caso de las semillas de pequeño tamaño de frutos como el higo y la mora, puede incluso que se incorporaran al depósito como material fecal.

En la figura 1 se señalan varios usos potenciales de la vegetación que darían como resultado residuos vegetales urbanos: utilización de combustible y desarrollo de actividades industriales (artesanas y de construcción: techumbres, maderas), alimento, plantas medicinales y cama para el ganado. Es probable que entre el material depositado para el relleno del puerto romano de Irún se incluyeran abundantes restos de basura urbana. Tampoco habría que olvidar la existencia de especies que han podido llegar al yacimiento de forma accidental, aunque aspectos relacionados con la dispersión de semillas en excrementos de animales como las aves y el ganado, en la ropa, por el viento, agua o las personas, raramente pueden ser evaluados en las muestras arqueológicas (Wilcox, 1977).

\subsection{Especies de importancia económica}

En el mundo clásico aumentaron los contactos entre diferentes regiones europeas. Una gran variedad de plantas de importancia económica fueron trasladadas a zonas donde antes no existían, bien mediante la introducción de la especie ya domesticada para su uso agrícola u hortícola, o bien mediante la importación. En las zonas costeras del occidente mediterráneo estos contactos a gran escala comenzaron con las primeras migraciones de colonos griegos y fenicios (Marinval, 1988). A pesar de la falta de información directa existente al respecto, se suele asumir que en el área atlántica estas innovaciones llegarían con posterioridad, particularmente en época romana.

Los romanos parecen actuar, por lo tanto, como difusores de nuevos productos tanto en esta zona como en la Europa septentrional (Greig, 1983). Son grandes conocedores de la agricultura, la horticultura y la silvicultura. Uno de los fundadores de la ciencia agraria fue precisamente el hispano Columela (4 a. C. -54 d. C.) y sus tratados De re rustica y De arboribus fueron muy difundidos (Bauer, 1991). La expansión romana supuso un revulsivo en el ámbito de las comunicación tanto de materias como de ideas. Allá donde se instala en el occidente y norte europeo introduce o importa una serie de pro- 
ductos estándar entre los que se encuentran abundantes especies vegetales domésticas, generalmente propias de áreas más cálidas: el Oriente Próximo o la Europa mediterránea. El ejército romano actúa muchas veces como agente de romanización y difusor de estos productos (Dickson, 1989).

Hemos considerado plantas de importancia económica aquéllas que han jugado tradicionalmente un papel importante en la subsistencia humana (alimentación, textiles, etc.). Entre éstas se distinguen varios tipos:

a) Las necesariamente cultivadas: Triticum.

b) Árboles o arbustos frutales: Vitis, Prunus domestica/insititia, Prunus cerasus, Persica vulgaris, Ficus carica y Olea europaea.

c) Árboles y arbustos silvestres: Corylus avellana, Rubus fruticosus, Prunus spinosa y Juglans regia.

a) Entre los cultivos destaca el trigo por su importancia en la economía de época romana. $\mathrm{Si}$ bien tenemos muy pocos datos acerca del desarrollo de la agricultura cerealística -generalmente acompañada de leguminosas- en el País Vasco cantábrico, sabemos que en esta zona se encuentra plenamente desarrollada para la Edad del Bronce, en el segundo milenio antes de Cristo (Zapata, inédito) y con toda probabilidad, con anterioridad (Iriarte, 1994). La evidencia proporcionada por un único grano carbonizado en las muestras de Irún no permite extraer conclusiones más allá de la mera presencia. Esto es debido al escaso volumen de tierra que se ha procesado así como al tipo de depósito del que procede. El muestreo sistemático de contextos urbanos y de carácter doméstico permitiría sin duda obtener una mayor información acerca de la tecnología, el papel de los cereales en la economía de subsistencia y las prácticas agrícolas desarrolladas en el yacimiento (Hillman, 1981 y 1984).

b) Los datos que existen sobre el desarrollo de la arboricultura en el País Vasco son igualmente escasos. Los resultados de análisis realizados en otras zonas de la península ibérica y de Francia hacen pensar en un desarrollo más tardío de estas especies en zonas atlánticas como Guipúzcoa, en muchos casos sólo a partir de la época romana (higo, ciruela, cereza o guindo...). Según D. Zohary y $\mathrm{M}$. Hopf (1993) la arboricultura es un tipo de técnica que se desarrolla en el Oriente Próximo varios milenios más tarde que la agricultura cerealística y por lo tanto su difusión a Occidente es también posterior. Consiste en la domesticación de árboles frutales, es decir, en alterar la biología reproductora de la planta que cambia su reproducción sexual por la vegetativa. Mediante la propagación de clones los seres humanos pueden seleccionar y duplicar aquellos individuos que proporcionan frutos excepcionales asegurándose así el genotipo deseado. Sólo unas pocas especies como el almendro o el nogal se han mantenido también a partir de la semilla. Según estos autores, en Oriente Próximo los primeros árboles frutales domesticados son el olivo, la vid, el higo, la palmera datilera y la granada, precisamente aquellos que se reproducen más fácilmente de forma vegetativa. Para otros frutales como el manzano, peral, ciruelo o cerezo no hay evidencia definitiva de su cultivo hasta el primer milenio antes de Cristo y su impulso se conoce en época clásica entre griegos y romanos que a su vez lo exportaron hacia occidente. Éstas últimas son especies que necesitan de métodos de reproducción más complicados como el injerto.

En las tres muestras estudiadas en Irún se han identificado semillas de Vitis vinifera (vid). La vid es una de las plantas clásicas de Europa que junto al olivo, la higuera y la palmera conforman el grupo más antiguo de árboles frutales alrededor de los cuales se desarrolló la horticultura (Zohary y Spiegel-Roy, 1975). Es una especie que se desarrolla especialmente en la región mediterránea aunque tolera condiciones más frías y húmedas que el olivo. Según estos mismos autores, la vid silvestre Vitis vinifera subsp. sylvestris se extiende por la zona cantábrica de la península ibérica. Otros autores (Rivera y Obón de Castro, 1991) afirman que las diferencias entre las vides cultivadas, subsp. vinifera y las silvestres, subsp. sylvestris no son tan grandes y constantes como para separarlas en dos subespecies. Según D. Zohary y M. Hopf (1993), los primeros datos claros de domesticación de Vitis procederían de contextos calcolíticos en el Próximo Oriente. Según Marinval (1988), en Francia la variedad silvestre aparece en yacimientos mesolíticos y su cultivo se documenta en la Edad del Hierro al parecer introducida por los colonos griegos. Sin embargo, D. Rivera y M. J. Walker (1989) señalan la presencia de semillas de vid en yacimientos de la península ibérica desde época paleolítica y proponen que la explotación de esta planta así como la tecnología relacionada con ella se desarrollaron en ambos extremos del Mediterráneo entre los años 4500 y 4000 B.P. Según otros autores, en la península ibérica la presencia de poblaciones silvestres de vid se remonta al Neolítico Medio - Final (Buxó, 1990; Hopf, 1991), aunque su cultivo fue impulsado en época romana. En el País Vasco el macrorresto de vid más antiguo procede del nivel P.III.b del poblado de la Edad del Hierro de Cortes de Navarra, situado en la margen derecha del río Ebro, en el 
límite entre Navarra y Aragón (Cubero, 1990). M. F. Sánchez Goñi (en prensa) ha identificado dos granos de polen de Vitis en el estuario del Bidasoa en un depósito fechado en un momento posterior a $2740 \pm 90$ B.P. El hecho de que la vid no se haya documentado en momentos anteriores podría hablar de una explotación tardía de la especie en esta zona.

En la muestra CSI - 8, correspondiente a la fase de ampliación del puerto, se han identificado dos huesos de ciruela (Prunus domestica / insititia). Se sabe muy poco sobre el inicio de la domesticación del ciruelo. En la zona del Danubio existen restos preneolíticos que se parecen a las ciruelas domésticas espontáneas actuales, por lo que pudo ser un elemento indígena en Europa central. Los restos que se han identificado en contextos neolíticos y de la Edad del Bronce en Italia, Suiza, Austria y Alemania parecen también proceder de la recolección de ciruelas silvestres. La documentación más antigua que existe sobre injertos en ciruelo es de época romana (Zohary y Hopf, 1993). Para la cornisa cantábrica, estos son los primeros ejemplares arqueológicos, y en Francia la ciruela tampoco se ha reconocido antes de la época romana. Su comercio a escala europea está atestiguado en este momento y por lo tanto su presencia en Irún puede ser producto de esta actividad o de un cultivo local introducido por los romanos.

Se han identificado un total de 11 huesos de Prunus cerasus vulgaris (guinda) en las muestras procedentes de Irún. El guindo es un tipo de cerezo característico de las zonas más frescas y templadas del Viejo Mundo. Según D. Zohary y M. Hopf (1993) se cultivan dos tipos de «cerezos»: el diploide Prunus avium L. (cereza) y el tetraploide Prunus cerasus L. (guindo). Este último tiene frutos rojos de un sabor ácido característico. En la actualidad existen ejemplares espontáneos de guindo en Europa central y occidental, pero se cree que derivan de la variedad cultivada que probablemente evolucionó bajo cultivo como resultado de un cruce entre el Prunus avium cultivado y Prunus fruticosa Pallas, un arbusto de Europa oriental y central de frutas demasiado astringentes como para ser consumidas. Según estos autores, las cerezas se recolectarían de forma silvestre mucho antes del comienzo de su cultivo. Existen hallazgos en poblados neolíticos de Europa central que parecen responder a formas silvestres. El primer dato sobre el cultivo del cerezo es de época clásica: Plinio menciona que Lúculo, en el siglo I a.de C., introdujo en Roma una variedad superior de cereza procedente de la zona del Ponto. Para la cornisa cantábrica son los primeros ejemplares de guindo o cerezo identificados hasta el momento. En Cataluña, Buxó (1994) ha recuperado restos de Prunus avium/cerasus en un contexto de la Edad del Hierro del Vallès occidental. La presencia de los restos de Irún parece ser consecuencia bien de una introducción del cultivo del guindo en época romana o bien de una importación comercial.

Persica vulgaris (melocotón) aparece por primera vez como planta hortícola en época clásica a la vez que el albaricoque y el membrillo. De acuerdo con los datos aportados por la arqueobotánica el melocotón llega al Próximo Oriente y a Europa en época clásica. Los primeros datos sobre su cultivo proceden de China hacia el 2000 B.C. y los romanos no lo cultivaron hasta el siglo I de nuestra era (Zohary y Hopf, 1993). A pesar de su incorporación tardía al conjunto de plantas cultivadas, Persica vulgaris se extendió rápidamente por la cuenca mediterránea y la zona de influencia romana como demuestran los hallazgos de Irún.

En el caso de los huesos de melocotón recuperados en CSI nos encontramos ante los primeros ejemplares tanto de la cornisa cantábrica como de la península ibérica excepto los hallados en un pecio romano cercano a Gerona (Hopf, 1991, citando un trabajo de Ramón Buxó). En Francia, su presencia en yacimientos no se señala hasta el siglo II de nuestra era aunque P. Marinval (1988) apunta, basándose en datos inéditos, la posibilidad de una introducción anterior. J. André (1981) y M. H. Callender (1965) (citado en Marinval, 1988) señalan la práctica romana de conservar melocotones en ánforas con vino, por lo cual determinar si la presencia de huesos en Irún se debe al cultivo local o a técnicas de conservación de frutos llegados a través del comercio es problemática.

Se han identificado abundantes semillas de Ficus carica (higo) en las muestras arqueológicas de Irún. La higuera comenzó a cultivarse en el Mediterráneo oriental, donde se localizan sus antecesores silvestres. Éstos se distribuyen ampliamente por todo el Mediterráneo en formaciones de maquis y garriga. En su forma silvestre, la higuera necesita para la fecundación de un agente polinizador, el Blastophaga grossorum (Aizpuru, 1990). Bajo cultivo, su propagación es vegetativa y el agricultor mantiene así el genotipo deseado. Los principales cambios de este árbol bajo domesticación fueron por lo tanto el paso a la propagación vegetativa de clones femeninos, el aumento del tamaño y contenido en azúcar del higo, la introducción de la polinización artificial y la selección de clones que no necesitan la fecundación para formar los higos. Es probable que el comienzo del cultivo de la higuera se produ- 
jera a la vez que el del olivo y la vid (Zohary y Hopf, 1993).

En Francia el higo no se ha identificado hasta la segunda Edad del Hierro (Marinval, 1988). En la península ibérica se ha reconocido en cuatro yacimientos arqueológicos (Hopf, 1991), desde época calcolítica en la Cueva de los Murciélagos de Córdoba (s. análisis de Leonor Peña-Chocarro), en Murcia y en el Bronce Argárico en Almería (Buxó, 1990). En las semillas no podemos utilizar criterios anatómicos para determinar si se trata de higos silvestres o cultivados; sin embargo, en el País Vasco no existe la higuera silvestre, por lo que necesariamente los ejemplares tuvieron que ser fruto de una introducción o producto del intercambio comercial en forma de higo pasa o seco, práctica ampliamente documentada (Wilcox, 1977; André, 1981).

Se han identificado dos huesos de Olea europaea (olivo), ambos en la muestra CSI -1. El antecesor silvestre, var. sylvestris Brot. o acebuche se distribuye en los países que rodean la cuenca del Mediterráneo, acompañando a las encinas, quejigos y alcornoques o formando parte de los matorrales que resultan de su degradación (Aizpuru, 1990). Recientemente se han localizado algunos acebuches en la zona costera de la cornisa cantábrica, en Asturias, Cantabria y Vizcaya (Javier Loidi, com. pers.). El olivo cultivado es muy similar al silvestre aunque presenta gran variación en el tamaño, forma y contenido en aceite de sus frutos, con gran variedad de formas locales. Los frutos del acebuche son más pequeños, con un mesocarpo menos carnoso y con menos aceite, pero su hueso no es mucho más pequeño que el de la forma cultivada. La similitud morfológica entre las semillas de ambos tipos (Liphschitz et al., 1991) impide que podamos distinguirlos en las zonas donde existe la variedad silvestre, pero éste no parece ser el caso de Guipúzcoa. Es probable que en el Mediterráneo la aceituna se aprovechara económicamente mucho antes de comenzar el cultivo y la manipulación del olivo. Bajo domesticación, se altera la reproducción natural por semilla del árbol. Las variedades cultivadas son de hecho clones que se mantienen mediante propagación vegetativa. El cultivo del olivo comenzó probablemente en la zona de Levante del Oriente Próximo y se introduciría en el Mediterráneo occidental en el primer milenio antes de Cristo de la mano de colonos fenicios y griegos (Zohary y Hopf, 1993).

La aceituna, suponemos que la variedad silvestre, se identifica en yacimientos arqueológicos de la península ibérica desde el Neolítico, existiendo bastantes evidencias en yacimientos del Calcolítico y Bronce Antiguo de Almería y Ciudad Real (Buxó,
1990). Igualmente en Francia hay hallazgos -todos de la zona mediterránea- de épocas similares (Marinval, 1988).

A pesar de que en Guipúzcoa no ha existido la variedad silvestre, el cultivo de Olea sí se ha dado históricamente en la vertiente meridional del País Vasco. El olivo se considera un buen indicador del clima mediterráneo; por ello prácticamente descartamos su cultivo en la zona del Bidasoa en época romana: se puede afirmar que se trata de un producto importado. Debido a su fácil conservación, la aceituna sirvió como un importante artículo de comercio desde la Antigüedad y su intercambio entre diferentes áreas de influencia romana está ampliamente documentado.

c) Entre los frutos silvestres que pudieron ser aprovechados por la población romana de Irún se encuentra Rubus agg. fruticosus (mora), de la que se han identificado abundantes semillas en las tres muestras estudiadas en el yacimiento de la calle Santiago de Irún.

El género Rubus, de la familia de las Rosáceas, es excepcionalmente rico en especies y formas. Se extiende por las zonas templadas de Europa, Asia y América. La mayoría de las especies cuentan con frutos comestibles, un fruto apocárpico compuesto de pequeñas drupéolas agrupadas en una infrutescencia carnosa -la mora- de color rojo o negro. Los táxones presentan una alta tasa de hibridación que dificulta la identificación de las especies (Aizpuru, 1990). Aparecen frecuentemente en contextos arqueológicos europeos desde el Neolítico hasta la Edad Media (Zohary y Hopf, 1993). En Francia se ha señalado su uso en poblados palafíticos del Neolítico Final (Marinval, 1988). En la península ibérica, a pesar de que su consumo en la Prehistoria tuvo que estar muy extendido, los únicos restos que se han identificado hasta ahora proceden de yacimientos de la Edad del Hierro catalanes (Castro y Hopf, 1982 en Buxó, 1990; Buxó, 1994). Por lo tanto, los de Irún son los primeros restos de la cornisa cantábrica.

Se han recuperado huesos de Prunus spinosa (endrino) en dos de las muestras estudiadas en Irún. Esta rosácea se extiende en los bosques planifolios claros y matorrales, setos, bordes de caminos y espacios abiertos en general. El endrino es un arbusto silvestre muy intrincado y ramoso con fruto en drupa globosa de 10 a $15 \mathrm{~mm}$. de color azul-negruzco, comestible y con pulpa de sabor ácido y áspero. Las drupas maduran al final del verano y contienen taninos, ácidos, azúcar y vitamina C (Rivera y Obón de Castro, 1991). A pesar de que tuvo que ser un fruto ampliamente utilizado por los seres humanos 
por lo menos desde el inicio del Holoceno, los únicos restos arqueológicos de endrino identificados en la península ibérica proceden de Cataluña y del País Vasco. En Cataluña se han reconocido en el abrigo mesolítico de El Gai (Barcelona) y en la Cueva 120 de Gerona (Buxó, 1991). El uso de esta especie en yacimientos arqueológicos vascos se documenta desde el Epipaleolítico según un trabajo que estamos realizando en la actualidad en el norte de $\mathrm{Na}$ varra. Para época romana, los restos de Irún son los primeros documentados.

Se tienen muy pocos datos sobre la domesticación de Juglans regia L. (nogal) aunque la información aportada por la palinología es muy importante. Las formas silvestres del nogal se distribuyen por los Balcanes, norte de Turquía, sur del Caspio, el Cáucaso, Asia central y China occidental y producen frutas más pequeñas que las cultivadas. El cultivo de esta especie depende básicamente del injerto de los clones seleccionados pero, al igual que la almendra, se puede también cultivar a partir de la semilla. La evidencia palinológica parece apuntar al noreste de Turquía, el Cáucaso y el norte de Irán como las áreas más posibles de domesticación del nogal (Zohary y Hopf, 1993).

En cuanto a Europa occidental, la nuez se ha identificado en los poblados palafíticos de la zona oriental de Francia desde el Neolítico Final (Marinval, 1988) y en la península ibérica se han reconocido macrorrestos en un poblado ibérico de Murcia (Buxó, 1990) así como en el yacimiento romano de Vilauba en la comarca de Bañoles (Buxó, 1994). Jalut (1992) señala que esta especie llega al Pirineo hacia el año 2000 B.P. y el análisis de M.F. Sánchez Goñi (en prensa) muestra su existencia en el estuario del Bidasoa con posterioridad a la última datación de C14 que proporciona $(2740+90$ B.P.), asociado a los primeros pólenes de Cerealia y Castanea. En otros yacimientos de Euskal Herria (El Castillar y La Peña en Navarra y Mulisko Gaina en Guipúzcoa) se ha recuperado polen de esta especie en niveles protohistóricos (M.J. Iriarte, com. pers.). Los macrorrestos aparecidos en CSI consisten en fragmentos del endocarpo leñoso o cáscara de la nuez acompañados de un fruto inmaduro, procedente de la muestra CSI - 8. La presencia de este fruto inmaduro confirma la existencia de Juglans en las inmediaciones en época romana.

Se han identificado fragmentos de pericarpo o cáscara de Corylus avellana (avellano) en todas las muestras analizadas. Esta especie se distribuye de forma silvestre por casi toda Europa formando parte del subsuelo y orlas de bosques caducifolios, generalmente en sitios umbríos y frescos. En el País
Vasco es frecuente en la mitad septentrional (Aizpuru et al., 1990) y se ha identificado a lo largo de toda la secuencia palinológica (desde hace unos 8.000 años) del estuario del Bidasoa (Sánchez Goñi, 1994). Según esta misma autora (1992) el polen de Corylus está también presente en la cueva de Urtiaga en Guipúzcoa, donde aparece hace 8.000 años en el Boreal. C. Peñalba (1992) ofrece resultados similares $(8.290 \pm 140$ B.P. $)$ para la expansión del avellano según la secuencia que ha estudiado en la laguna colmatada de Quintanar de la Sierra (Burgos). La mejora climática del Holoceno permitió por lo tanto el desarrollo de árboles mesotermófilos entre los que se encuentran Corylus, Quercus y posteriormente Fagus.

Entre los usos de esta especie, destacan los comestibles y los constructivos y artesanales, ya que sus varas han sido frecuentemente empleadas para la fabricación de entramados y cestos (Rivera y Obón de Castro, 1991). Existe abundante documentación sobre la gestión tradicional en Europa de bosques de avellano en ciclos cortos (Rackham, 1980). En Inglaterra, por ejemplo, gracias al estudio de los anillos en entramados de origen arqueológico, se ha podido determinar una gestión de esta especie en rotaciones de cinco a siete años.

En lo que respecta a los macrorrestos vegetales de origen arqueológico, su presencia se atestigua ampliamente desde niveles epipaleolíticos en Francia (Marinval, 1988). Según los análisis arqueobotánicos que estamos llevando a cabo en varios yacimientos del País Vasco, la avellana es el fruto más frecuente de los recuperados desde época epipaleolítica.

\subsection{CONCLUSIONES}

Se han estudiado tres muestras arqueobotánicas procedentes de las dos fases detectadas durante la excavación del yacimiento romano de la calle Santiago de Irún. La primera fase corresponde a la fundación de la estructura portuaria, hacia el año 50 de nuestra era, y la segunda a la ampliación de la misma a fines del siglo II o comienzos del III.

Los resultados permiten identificar un depósito en el que confluye material botánico de origen vario. Por un lado, el que corresponde a la vegetación de las inmediaciones del yacimiento (estuarina y de ribera) y por otro lo que parecen ser desechos urbanos de diverso origen (fecal, alimentos, combustible, etc.) acompañados de especies nitrófilas características de un medio alterado.

La población del Irún romano tuvo acceso a una 
amplia gama de recursos vegetales. Al igual que durante la prehistoria, las plantas silvestres juegan todavía un papel importante en la alimentación del grupo humano, pero la mayor aportación a la historia vegetal de la época consiste en la presencia, por primera vez en la cornisa cantábrica, de una gran variedad de especies domésticas, cultivadas.

Atendiendo al origen de los productos vegetales de interés económico identificados, se pueden establecer estos grupos: $\left.2^{a}\right)$

a. Importados con seguridad: aceituna (fase

b. Importados con bastante probabilidad, aunque su cultivo pudo haber sido introducido en la zona en época romana: ciruelas (fase $2^{a}$ ), guindas, higos (fases $1^{\mathrm{a}}$ y $2^{\mathrm{a}}$ ) y melocotones (fase $2^{\mathrm{a}}$ ).

c. Cultivados en las inmediaciones desde época prehistórica aunque también pudieron ser producto de intercambio con otras zonas excedentarias: trigo, uvas.

d. Recolectados en las inmediaciones en su forma silvestre o quizá en bosques cercanos gestionados: mora, endrina, nuez, avellana.

Está ampliamente documentada en época romana la existencia de un comercio a gran escala de todo tipo de productos. Oiasso se localiza en una zona de alto interés estratégico, en un paso natural de los Pirineos y junto a importantes yacimientos mineros. Allí confluían las calzadas procedentes de (a) Tarraco, por el Valle del Ebro vía Pamplona, (b) Emerita, por la vía de la Plata por León y Briviesca, y (c) Augusta Bracara, bordeando el norte peninsular paralela a la costa. La plaza comercial de Irún constituía un punto de encuentro y redistribución de productos elaborados en diferentes centros. La abundante cerámica recuperada en el yacimiento corresponde a centros de fabricación situados en un radio que llega desde las costas del Canal de la Mancha hasta los Alpes y la Rioja (Urteaga, 1995; Urteaga y López, 1994). Oiasso pudo ser un centro dependiente de Burdigalia, Burdeos, ejerciendo funciones de intermediaria. Hasta la primera mitad del siglo I d.C. los productos de la Hispania mediterránea que acceden a Irún lo hacen a través de Burdeos. Desde allí se redistribuían al mercado hispano del noroeste por la vía Burdeos-Astorga y a través de la navegación de cabotaje (Benito, 1988). Se ha considerado a Oiasso una statio en la ruta del Cantábrico, a medio camino entre las costas de Hispania y Galia. La ciudad abastecería a Burdigalia de metales y mineral de hierro y, a cambio, las naves regresarían con vajillas, manufacturas y otros productos entre los que se encontrarían los alimenticios (Rodríguez Salis, 1973; Urteaga, 1995).
Las especies que hemos identificado, a pesar de su carácter perecedero de forma natural, pueden ser transportadas a grandes distancias siguiendo determinadas técnicas de conserva en las que los romanos eran ya expertos (André, 1981): en forma de pasa seca (higos, uvas, ciruelas...) o en ánforas con líquidos (aceituna, melocotón...). Por este motivo se hace difícil determinar la naturaleza local o alóctona de algunas de las especies vegetales que hemos identificado, pues es posible que (1) Irún sólo actúe como centro redistribuidor del producto, (2) correspondan a importaciones de otras zonas de Hispania o Galia. Éste sería, por ejemplo, el caso de la vid ya que, aunque se cultivara en la costa guipuzcoana en esta época, existe la posibilidad de que los ejemplares que hemos hallado procedan de otras áreas productoras a mayor escala. El estudio de las zonas de habitación del centro urbano de Oiasso podría ofrecer más datos acerca de la importancia de la producción y consumo de estas especies entre la población local.

En cuanto al aspecto metodológico, es necesario recordar la necesidad de realizar muestreos arqueobotánicos de forma sistemática en todas las excavaciones. Los restos botánicos, junto al resto de la evidencia arqueológica, proporcionan una valiosa información sobre las actividades humanas y contribuyen al conocimiento del pasado. Irún es un buen ejemplo del potencial que ofrece el estudio de material de este tipo.

\section{Agradecimientos:}

Agradecemos la confianza de la directora de la excavación, Mertxe Urteaga al proporcionarnos el material estudiado. Muchas gracias a Gordon Hillman por su ayuda en la fase de identificación de restos y a Francesco d'Errico por su ayuda en la elaboración de las fotografías. Agradecemos igualmente los comentarios y sugerencias de $\mathrm{M}^{\mathrm{a}} \mathrm{F}$. Sánchez Goñi, $M^{a} J$. Iriarte y M. Izquierdo.

\section{BIBLIOGRAFÍA}

ANDRÉ, J., 1981: L'alimentation et la cuisine à Rome. Les Belles Lettres, Paris.

Aizpuru, I., Catalán, P., y Garín, F., 1990: Guía de los árboles y arbustos de Euskal Herria. Gobierno Vasco. Vitoria - Gasteiz.

Aseguinolaza, C., Gómez, D.; Lizaur, X., Montserrat G., Morante, G., Salaverría, M.R., y UriBe-Echevarría P. M ${ }^{\mathrm{a}}$., 1988: Vegetación de la 
Comunidad Autónoma del País Vasco. Gobierno Vasco. Vitoria.

Aseguinolaza C., Gómez, D. Lizaur, X., Montserrat G., Morante, G., Salaverría, M. R., UriBe-Echevarría P. Ma , y Alejandre, J. A., 1984: Catálogo florístico de Álava, Vizcaya y Guipúzcoa. Gobierno Vasco. Vitoria.

Bauer, E., 1991: Los Montes de España en la Historia. Ministerio de Agricultura, Pesca y Alimentación y Fundación Conde del Valle de Salazar. Madrid.

Benito, A. M., 1988: «Cerámicas del yacimiento submarino del cabo de Higer (Hondarribia)». Munibe (Antropologia-Arkeologia), 40, 123-163.

Buxó, R., 1990: Metodología y técnicas para la recuperación de restos vegetales en yacimientos arqueológicos. Cahier Noir, 5. Girona, 1-63.

Buxó, R., 1993: Des semences et des fruits. Cueillette et agriculture en France et en Espagne mediterranéennes du néolithique à l'âge du fer. Tesis de Doctorado inédita. Université Montpellier II.

CAllender, M. H., 1965: Roman Amphorae. Oxford University Press.

Castro, Z. y Hopf, M., 1982: «Estudio de los restos vegetales en el poblado protohistórico Illa d'en Reixac (Ullastret, Girona)». Cypsela 4, 103-111.

Cubero, C., 1990: «Análisis paleocarpológico de muestras del Alto de la Cruz II: campañas 1986/ 88». Trabajos de Arqueología Navarra 9, 199217.

De Moulins, D. (Ed.), 1990: The upper Walbrook valley in the Roman period. Environmental Analysis. Museum of London y Council for British Archaeology.

Dickson, 1989: «The Roman army diet in Britain and Germany. Archäobotanik». Dissertationes Botanicae 133, 135-154.

García, L. M., 1992: Plantas comestibles. Gobierno de Navarra.

Genders, R., 1988: Plantas silvestres comestibles. Ed. Blume. Barcelona.

GERARD, J., 1985: Gerard's Herbal (1636). Ed. M. Woodward. London.

GreEN, F. J., 1982: «Problems of interpreting differentially preserved plant remains from excavation of Medieval urban sites». En: HALL, A. R. y Kenward, H. K. (Eds.): Environmental archaeology in the urban context. CBA Research Report, 43.

GreIG, J., 1983: «Plant foods in the past: A review of the evidence from Northern Europe». Journal of Plant Foods 5, 179-213.
Hastorf, C. A. y Popper, V. S., 1988: Current Paleoethnobotany. The University of Chicago Press. Chicago.

HATHER, J., 1993: Identification of carbonized parechimatous tissue. Cambridge Univ. Press.

Hillman, G., 1981: «Reconstructing crop husbandry practices from charred remains of crops», en: Mercer, R. (Ed.): Farming Practice in British Prehistory. Edinburgh University Press. Edinburgh.

- 1984: «Interpretation of archaeological plant remains: The application of ethnographic models from Turkey», en: van ZeIsT, W. y CASPARIE, W. A. (eds.): Plants and Ancient Man, Rotterdam/ Boston, 1-41.

Hopf, M., 1991: «South and Southwest Europe», en: van ZeIst, W. et al.: Progress in Old World Palaeoethnobotany. A. A. Balkema/Rotterdam/ Brookfield, 241-277.

IRIARTE, M. J., 1994: «Estudio palinológico del nivel sepulcral del yacimiento arqueológico de Pico Ramos (Muskiz, Bizkaia)». Cuadernos de Sección. Prehistoria-Arqueología 5, 161-179.

Hubbard, R. N. L. B., 1976: «Crops and climate in prehistoric Europe». World Archaeology 8, 159 168.

JALUT, G., 1992: «Le paleoenvironnement de la moitié occidentale du versant nord des Pyrenées de 40.000 B.P. à l'actuel: étapes de la déglaciation et histoire de la végétation», en: CEARreta, A. (Ed.): The Late Quaternary in the Western Pyrenean Region. U.P.V / E.H.U. Vitoria - Gasteiz, 125-141.

LANGer, R. H. M. y Hill, G. D., 1981: Agricultural Plants. Cambridge Univ. Press.

Liphschitz, N., Gophna, R., HaRTMAN, M. y Biger, G., 1991: «The Beginning of Olive (Olea europaea) Cultivation in the Old World: A Reassessment». Journal of Archaeological Science 18, 441-453.

MarinVAl, P., 1988: L'alimentation végétale en France. Du Mésolithique jusqu'à l'Âge du Fer. C.N.R.S. Paris.

PARKER, A. J., 1973: «The evidence provided by underwater archaeology for Roman trade in the Western Mediterranean», en: D. J. BLACKMAN (Ed.): Marine Archaeology. Colston Papers, 23, 361-382.

Peña-Chocarro, L., 1995a: «Avance preliminar sobre los restos vegetales del yacimiento de la Edad del Bronce de Peñalosa (Baños de la Encina. Jaén)». $1^{\circ}$ Congresso de Arqueologia Peninsular. Trabalhos de Antropologia e Etnologia 35 (1), 159-167. 
- 1995b: Prehistoric Agriculture in Southern Spain from the Neolithic to the Bronze Age: the application of ethnographic models. Tesis de doctorado inédita. University College London.

PeÑalba, C., 1992: «La vegetación y el clima en los montes vascos durante el Pleistoceno superior y el Holoceno según los análisis palinológicos», en: Cearreta, A. (Ed.): The Late Quaternary in the Western Pyrenean Region. U.P.V / E.H.U. Vitoria - Gasteiz.

RACKHAM, O., 1980: Ancient Woodland. Edward Arnold. London.

RAMIL, P., 1993: «Paleoetnobotánica de yacimientos arqueológicos holocenos de Galicia (N.O. Cantábrico)». Munibe (Antropologia-Arkeologia) 45, 165-174.

Rivera, D. y Obón de Castro, C., 1991: La guía de INCAFO de las plantas útiles y venenosas de la península ibérica y Baleares (excluídas medicinales). INCAFO. Madrid.

Rivera, D. y WALKer, M. J., 1989: «A review of Palaeobotanical findings of early Vitis in the Mediterranean and of the origins of cultivated grapevines, with special reference to new pointers to prehistoric exploitation in the Western Mediterranean». Review of Palaeobotany and Palynology 61, 205-237.

RoDRíGUEZ SALIS, J., 1973: «Romanización del Bidasoa (Datos para su estudio)». II Semana de Antropología Vasca, 363-366.
SÁnchez GoÑı, M. F., 1992: «Analyse palynologique de sites préhistoriques du Pays Basque: premiers resultats pour les grottes de Lezetxiki et Urtiaga», en: Cearreta, A. (Ed.): The Late Quaternary in the Western Pyrenean Region. U.P.V / E.H.U. Vitoria - Gasteiz.

- 1994: Análisis polínico del depósito estuarino del Bidasoa, (en prensa). University of Cambridge.

Urteaga, M., 1995: El puerto romano de la calle Santiago de Irún. Ayuntamiento de Irún / Arkeolan.

Urteaga, M. y LóPEz, M.M., 1994: «Los descubrimientos arqueológicos de la calle Santiago de Irún. Primera aproximación a las estructuras portuarias de época romana». Boletín de Estudios del Bidasoa, 11, 7-17.

VÁzQuez, G., 1991: Plantas medicinales en el País Vasco. Ed. Txertoa. San Sebastián.

VV.AA., 1984-1992: Arkeoikuska. Gobierno Vasco. Vitoria - Gasteiz.

WILCox, G., 1977: «Exotic Plants from Roman Waterlogged Sites in London». Journal of Archaeological Science, 4, 269-282.

ZAPATA, L., (inédito): Informe preliminar y potencial arqueobotánico del yacimiento en cueva de Arenaza I (Galdames, Bizkaia). Campaña de 1992.

ZohaRY, D. y Hopf, M., 1993: Domestication of plants in the Old World. Clarendon Press. Oxford. 